\title{
Self-Assembled Monolayers (SAMs): Which Perspectives in Implant Dentistry?
}

\author{
Filiberto Mastrangelo ${ }^{1}$, Giulia Fioravanti ${ }^{2}$, Raimondo Quaresima ${ }^{2}$, Raffaele Vinci ${ }^{3}$, Enrico Gherlone ${ }^{3}$ \\ ${ }^{1}$ Department of Oral Science, University “G. D'Annunzio" of Chieti, Chieti, Italy; ${ }^{2}$ Department of Chemistry, Chemical Engineering \\ and Materials, University of L'Aquila, L'Aquila, Italy; ${ }^{3}$ Department of Oral Science, University “S. Raffaele" of Milan-Ateneo Vita \\ e Salute, Milan, Italy. \\ E-mail: filibertomastrangelo@hotmail.com, \{giulia.fioravanti, raimondo.quaresima\}@univaq.it
}

Received October $5^{\text {th }}, 2011$; revised November $14^{\text {th }}, 2011$; accepted November $27^{\text {th }}, 2011$.

\begin{abstract}
Self-assembled monolayers (SAMs) are ordered organic films formed by adsorption of an active organic coating on a solid surface. Their formation provides an alternative, highly innovative, to current traditional chemical treatments of the titanium surfaces. For this reason the structural phases, the formation and the growth of SAMs is described from a surface science point of view. Particulars are given to SAMs on titanium concerning surface morphology, chemical composition and affinity of specific head group for Ti surfaces (silanes, siloxane, phosphonates and phosphates). Preparation, coating methodologies, limitations and techniques used for the characterization of SAMs are reported. For their physicochemical characteristics and micro-nano scale features some perspectives of using SAMs in biomedical application are outlined.
\end{abstract}

Keywords: Titanium Surfaces, Implant Dentistry, Osteointegration, Self-Assembling Monolayers, Phosphates

\section{Introduction}

The biocompatibility of an osteointegrated titanium implant is correlated with its physical, mechanical and chemical characteristics. Moreover the superficial characteristics have a key role during the initial phases of osteointegration processes in relationship to titanium biomaterial and bone tissue [1]. More clinical and research studies were produced in order to modified the titanium surface with different chemical (acid oxidation, peroxidation, alkalization, crystalline hydroxyapatite deposition, electrochemical anodization) and physical approaches (compactation on particles, ion beam, pressure or chemical vapour deposition) [2]. With all this methods a macro, micro and nano-scale surface modification is obtained $[3,4]$. To improve the implant success rates the attention highlighted nano-scale features [5]. Therefore surface modification techniques such as lithography [6-19] and self-assembled monolayers (SAMs) were recently developed and investigated in implant dentistry [20-25]. While the lithography techniques require a considerable great development prior to clinical translation and application on implant surface $[26,27]$ the SAMs are more known and experimented in medicine [20,21].

\section{Self-Assembled Monolayers}

\subsection{Introduction on Self-Assembling Monolayers}

The first preparation and structural characterization of monolayer assemblies of oriented organic molecules were described by Nuzzo and Allara in 80s, [28-32] which dramatically changed surface science.

SAMs structures are ordered organic films in supramolecular chemistry [33-36], directed through noncovalent interactions (e.g., hydrogen bonding, metal coordination, hydrophobic forces, van der Waals forces, $\pi-\pi$ interactions, and/or electrostatic effects), formed by the adsorption (chemisorption) of an active organic coating on a solid surface.

SAM formation provides one easy route towards surface functionalization by organic molecules on selected metallic ( $\mathrm{Au}, \mathrm{Cu}, \mathrm{Ag}, \mathrm{Pd}, \mathrm{Pt}, \mathrm{Hg}$ and $\mathrm{C})$ as well as semiconducting surfaces $(\mathrm{Si}, \mathrm{GaAs}$, indium coated tin oxide etc.).

SAMs have shifted the focus of surface science from metals and metal oxides to surfaces composed of organic molecules, and allowed studies of surfaces in contact with solvents and of biologically relevant surfaces. They can be regarded as the interface between materials with 
totally different physical and chemical properties: metals, semiconductors, or other inorganic materials as organic and biological materials (polymers, biomolecules, other simpler organic molecules, etc.).

SAMs formation provides an alternative highly innovative to the current chemical treatments towards surface functionalization by amphiphilic molecules, which could be of great use for several practical applications such as chemical sensing (biosensors), adhesion (cell or protein), control of surface properties like wettability and friction, corrosion inhibition, patterning, semiconductor passivation, and organic electronics [37-50].

A SAM is a properly organized layer of amphiphilic molecules with a "head group" at the end having special affinity for a substrate; on the other end is present a terminal functional group connected by a "tail" (Figure 1).

The end functional groups (tail groups) could be modulated, and generally properly chosen to improve hydrophilic and hydrophobic properties of the substrate.

SAM formation process involves starting with bulk solution transport, sample surface preparation, surface adsorption and continuing with the two-dimensional organization on the substrate [51].

The chemisorption of hydrophilic "head groups" onto a substrate is followed by a slow two-dimensional organization of hydrophobic "tail groups"; adsorbate molecules form either a disordered mass of molecules or form a "lying down phase", where alkyl chains are parallel to the surface or are stacked into a striped phase, before reaching the standing-up phase (Figure 2).

The last phase is characterized by a re-arrangement into a systematic layer (crystalline or semicrystalline), until the growing left no area on the surface, forming the totally covered and packed single monolayer [51]. This later process can involve passage through one or more intermediate surface phases and can often be described using two-dimensional nucleation and growth models [52].

The kinetics of SAM formation and stability depend on

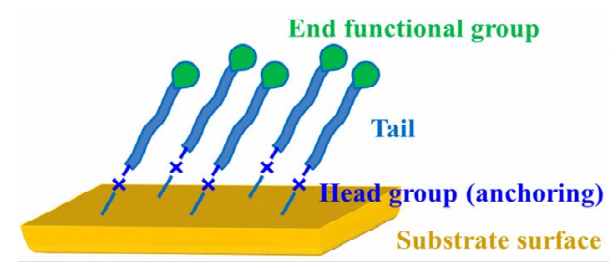

Figure 1. Representation of SAM structure.

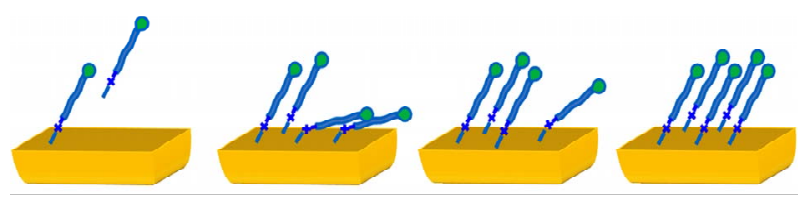

Figure 2. SAM formation. both preparation conditions and materials adsorbate and substrate properties.

The head group plays a critical role for the stability and packing order [53] and different groups ( $\mathrm{SH}, \mathrm{COOH}, \mathrm{OH}$, $\mathrm{NH}_{2}$ ) usually results in a decrease in the order of the monolayer than $\mathrm{CH}_{3}$ group.

The defect density decreases with increasing hydrocarbon chain length [54].

The final organization properties are dependent on the chain length, the adsorbate and the substrate. Steric hindrance and metal substrate properties affect the packing film density while chain length involves SAM thickness $[55,56]$.

An increasing level of attention has been given to the defects, caused by both external and intrinsic factors, within monolayer structures.

External factors include the surface preparation (roughness and surface defects), cleanliness of the substrate, method of preparation, and purity of the adsorbates. The absorption of various kinds of unwanted molecules makes SAM highly unstable.

SAMs intrinsically form defects due to the thermodynamics of formation as it happens in thiol SAMs on gold that typically exhibit monoatomic vacancy islands due to extraction of adatoms from the substrate and formation of adatom-adsorbate moieties.

Limited thermal $[57,58]$ and oxidative stability are also responsible for curtailing SAMs large scale use.

Due to their versatility and stability the most widely studied SAM are alkanethiols on gold and silanes on silicon.

From a biomedical point of view a wide variety of biomolecules and biomaterials involving proteins, peptides, DNA, carbohydrates, antibodies, and therapeutics, have been attached to SAMs for several applications [5963]. Therefore SAMs are highly promising for implanting functional molecules on surfaces or to modify chemicalphysical properties of themselves.

In the present study the perspective of using SAMs in implant dentistry was evaluated in terms of features, limitations, preparation methodology, characterization and applications.

\subsection{Self-Assembling Monolayers on Ti}

Commercial pure titanium (cpTi) and its alloys are widely used in orthopedic, oral and maxillofacial surgery as load bearing implants because of their superior mechanical properties, good biocompatibility with hard human tissues, and high resistance to corrosion.

$\mathrm{CpTi}$ and its alloys are highly reactive metals that readily passivate to form a protective oxide layer, tenacious and stable approximately 10 nanometers thick [64].

The native covering oxide is basically amorphous in 
crystal structure and morphologically homogeneous [6569], but this layer is irregular in thickness and composition, non-crystalline, and typically contaminated with various foreign elements taken from the surroundings.

The oxide layer provides a highly biocompatible surface and allows for bonding other materials to the metal surface or bone tissue appearing suitable for dental implants or prostheses.

Few reports of SAMs on Ti [70,71], stainless steel [37], tantalum [72], zirconium [73,74] or nitinol [37,75] are present in literature if compared to those on $\mathrm{Au}$.

On Ti surfaces for fabrication of individual monomolecular modification the attaching group of phosphonic acids or silanes are used.

However, the use of SAMs is strongly related to the chemical and physical stability of the thin film, which depend on several factors as:

1) surface morphology and chemical composition;

2) affinity of head group toward metal oxide;

3) coating methodology.

The focus on Ti surfaces used for medical applications has shifted from surface roughness to surface chemistry and a combination of chemical manipulations on the porous structure to mimic biological functions, for the purpose of inducing specific cell and tissue responses.

Surface modification of biomedical implants promotes improved biocompatibility and enhanced implant integration with the host.

\section{1) Surface morphology and chemical composition}

Surface roughness has been shown to be an influencing parameter for SAM characteristics, as it will determine the quality of the SAM in terms of its stability, degree of coverage, and order.

It is necessary to consider the topography at various scales: macro-roughness and micro- to nano-roughness, which differ for average surface roughness size of the order of microns to sub-microns up to nanometers, respectively.

To optimize SAMs deposition (in terms of minimizing defects) surfaces must undergo a basic pre- treatment to obtain clean and flat substrates. By using a proper solvent (such as acetone, methanol, ethanol or toluene) contaminants are removed from the surface.

To obtain a well-ordered and densely packed SAM, the surface of the substrate should be relatively smoothed by using mechanical polishing methods (such as silicon carbide grinding papers and diamond pastes as abrasive). The process of polishing with abrasives usually starts with coarse ones and graduates to fine ones.

Also surface chemical composition plays a fundamental role in SAMs formation, as phosphonic acids or silanes reactions with $\mathrm{Ti}$ surface is limited by hydroxyl adsorption sites to achieve full coverage.
Gas plasma was extensively used in the literature to pretreat metal oxides before the deposition of SAMs; oxygen plasma treatment is a common procedure to introduce hydroxyl groups on a Ti surface [76].

Acid etching is the simplest way to obtain hydroxylated Ti surfaces. Conventional chemical treatment consists in using oxygen peroxide or piranha solution (sulfuric acid and oxygen peroxide) to obtain a sufficient density of hydroxyl groups at the surface of Ti. If chemical pretreatments are not carefully controlled it is possible to have surface morphology modification, resulting the substrate corrosion and formation of a very porous surface, which is undesirable [70].

\section{2) Affinity of head group toward metal oxide}

The formation of a well-assembled monolayer depends on the purity of the adsorbant being used. The presence of even low levels of contaminants can result in a disordered, non-ideal monolayer.

Silanes/siloxanes and phosphonic acids/phosphonates are the most commonly organic reagents used for Ti surfaces.

\section{- Silanes/Siloxanes}

The organosilane derivatives $\mathrm{R}_{\mathrm{m}} \mathrm{SiX}_{\mathrm{n}}$ (where $\mathrm{X}$ is a chloride or alkoxy group and $\mathrm{R}$ is an organic group that can carry different functionalities) are known to react also in cpTi with hydroxylated surfaces to form monolayers.

Alkoxysilanes need specific $\mathrm{pH}$ values and relatively high concentration to form stable and densely packed monolayers, while trichlorosilanes require lower concentrations and shorter reaction times.

When alkyltrichlorosilane is used, $\mathrm{Si}-\mathrm{Cl}$ bonds react with the $\mathrm{OH}$ groups present on the surface of the substrate to form a siloxane network.

The assembly of alkylsilane monolayers is highly sensitive to solvent, temperature, and trace amounts of water.

Common long chain alkyl silanes used in the formation of SAMs are simple hydrocarbon, fluoroalkyl and end-group substituted silanes. Silanes with one hydrolysable group maintain interphase structure after deposition by forming a single oxane bond with the substrate. Silanes with three hydrolysable groups form siloxane (silsesquioxane) polymers after deposition, bonding both with each other as well as the substrate. The minimization of water condensation at the substrate can prevent the random aggregation and reaction among the silanes and increase attachment to the substrate. Formation of well-ordered oxane bonds with surface hydroxyl groups depends on the density or frequency of materials surface hydroxyl groups [33].

\section{- Phosphonic acid/Phosphonates}

Phosphonic acids, are somewhat less often character- 
ized compared to silanes and thiols, but are the becoming of great practical interest because of their ability to produce SAMs on a range of metal oxide surfaces $[73,77]$.

Organophosphonates and organophosphates are structurally similar. An organophosphate has four oxygens with an alkyl group connected via a phosphoester bond. Phosphonates have three oxygens with a carbon attached directly to phosphorus. The lack of a hydrolyzable P-O-C linkage makes phosphonate compounds more stable in aqueous solution and easier to make SAMs with than organophosphate compounds.

The reaction of long-chain alkylphosphonic acids with metal oxide supports leads to dense, well-ordered SAMs [78,79].

Phosphonates and phosphonic acids form SAMs on Ti surfaces by the formation of Ti-O-P bonds.

The deposition technique is based on SAMs made from aqueous alkyl phosphate solutions, which has the advantage of not using organic solvents [71,80]. Advantages of these SAMs compared to silane ones are a higher hydrolytic stability under physiological conditions and the fact that no surface conditioning (i.e., acid treatment) is required to obtain high coverage.

\section{3) Coating methodology}

SAMs methodology is divided in two approaches: gas phase and solution phase deposition [51].

Growth from the gas phase generally requires an experimental setup with vacuum chambers for better control of the cleanliness of the environment, the substrate and the substances and their respective temperatures as well as the applicability of essentially all the established techniques known with molecular resolution, used in surface science to determine the structure.

In gas phase deposition the substrate is located in a generic surface which allows for cleaning of the surface by ion sputtering and annealing and, through one additional port, the adsorbing molecules are dosed with a controllable flux [81].

In the traditional preparation of SAMs growth from solution the properly cleaned substrate has to be dipped into the corresponding diluted solution for a certain period of time and the monolayer will assemble [82].

The two principal methods common employed to coat phosponic acid SAMs on cpTi are (a) pre-treating Ti using gas plasma followed by solution phase deposition [71, 83] and (b) annealing-based deposition [77,84].

Aerosol sprayed technique is also used to form phosphonic acid SAMs onto cpTi surfaces from solution [77]. The spray process was followed by annealing, which consists in heating a thin film of phosphoric acid on the Ti surface, giving a strongly bound, ordered alkylphosphonate film. The subsequent heat treatment increases the covalent character of the bond between the metal substrate and the phosphate or phosphonate anchor groups [85-89].

A broad variety of organophosphates have been used for SAMs formation on cpTi by using a tethering by aggregation and growth (T-BAG)/annealing process [90].

Other strategy is based on the adsorption of the alkyl phosphate ammonium salts from aqueous solution [71].

\section{Preparation Methodology}

Considering the stability of phosphonic SAMs on cpTi or its alloys in the follow only this assembling technique and details will be discuss.

\subsection{Cleaning and Hydroxilating Procedure}

Prior to deposition, titania substrates were placed in a highly clean politetrafluoroethylene container and treated in an ultrasonic bath with water and a proper organic solvent (i.e. 2-propanol or ethanol) for 10 minutes. It is very important to place the samples in a vertical position to remove microscopically small particles, such as silicon powder, during the sonication. Such small particles cannot be removed by simply blowing them away, not even with a strong gas stream. The samples were removed from the organic solvent and rinsed with copious amounts of high-purity water; then blow-dried in a nitrogen stream followed by an additional cleaning in a UV-ozone cleaner for 30 minutes or in an oxygen-plasma cleaner for 2 minutes, right before the assembly process. This treatment resulted in completely hydrophilic surfaces.

\subsection{Spray Deposition}

The hydroxylated titanium substrates were sprayed (TLC sprayer and nitrogen) using a $0.75 \mathrm{mM}$ solution of the phosphonic acid in dry THF (tetrahydrofuran) at room temperature and allowed to dry at room temperature. The solvent was then evaporated under ambient conditions.

\subsection{Solution Deposition}

Immersion of clean titanium surfaces in tetrahydrofuran (THF) solution of phosphonic acid was carried out immediately after the cleaning because of the extreme susceptibility of these titanium films to adventitious hydrocarbon contamination. Upon removal the samples were rinsed in pure THF for $30 \mathrm{~s}$ and finally blown dry with filtered nitrogen.

\subsection{Solution Deposition from Water Soluble Salts}

Alkyl phosphates with different terminal functionalities can be deposited from aqueous solution by converting the free (water-insoluble) alkyl phosphoric acids into the corresponding water-soluble salts. Usually, a $1 \mathrm{mM}$ solu- 
tion of ammonium salt of the corresponding phosphate was used. After $48 \mathrm{~h}$, the $\mathrm{Ti}$ specimens coated with phosphate SAMs were rinsed in copious amount of running water.

\subsection{Annealing Process}

A strongly surface-bound film of alkanephosphonate can be formed on the Ti native oxide surface by heating the material prepared as described above (but before rinsing) at $120^{\circ} \mathrm{C}$ for $18 \mathrm{~h}$. Immersion of treated Ti samples in dry THF twice, for $5 \mathrm{~min}$ each, removed physisorbed phosphonic acid. Samples were then dried (room temperature, 0.1 Torr).

Surface coverage of chemisorbed phosphonates could be enhanced through repeated sequences of solution deposition, heating $\left(120^{\circ} \mathrm{C}, 18 \mathrm{~h}\right)$, and rinsing with THF.

\section{SAMs Characterization}

A SAM for its feature (chemical and topographic changes) could be considered a nano composite structure. Therefore it is necessary characterize, with high performing and specific techniques, the morphological evolution of the surface with respect the chemical pretreatment conditions and the SAM growth. During characterization the SAMs layer could be altered or modified by destructive test methods.

Parameters and properties of the Ti substrate, of the assembled monolayers [69,70] and the corresponding destructive (DT) or non-destructive measure techniques (NDT) are reported in Table 1.

\section{Discussion}

SAMs formation can provides a potential and economic method for obtaining designable physicochemical features of the titanium surface in order to promote the osteointegration. The technique appears particularly interesting due to the fact that the SAM can be considered a "multi compose" physicochemical thin film able to modify the critical chemical Ti surface characteristics.

The nano-scale structure layer of about several tens of nanometers $(20-30 \mathrm{~nm})$ may have a great influence the physiological and pathological healing process.

The length of the tails can be ruled by the number of carbon atoms, while the number of hydrophilic end groups could be modified controlling the hydroxylation process.

Moreover the roughness of the SAMs structure depends on the functional group and its package. Some authors [70] found that octadecyltrichlorosilane produced a great reduction of the pristine roughness, comparable to the dimensions of the atoms of the functional terminal group (few units on nanometer).

Furthermore different interactions between cells growth and implant Ti surfaces could role by the level of packing order of the chains.

Chemical nature of the terminal groups could favorite better interaction within bone cells and implant and biomimetics properties.

In order to obtain stable SAMs both the preparation conditions and the materials properties are critical. Therefore the substrate must be perfectly clean and the

Table 1. Characterization of a SAM and its substrate: parameters, properties and technique.

\begin{tabular}{|c|c|c|c|c|}
\hline Substrate & Assembled monolayers & Technique & DT & NDT \\
\hline Morphology & & SEM & - & $\mathrm{x}$ \\
\hline Contaminants-impurities & & SEM-EDX & - & $\mathrm{x}$ \\
\hline Roughness & & Laser Profilometry & - & $\mathrm{x}$ \\
\hline Thickness of titanium oxide & & XPS & $\mathrm{x}$ & - \\
\hline Hydrophilicity/surface wettability & & Water contact angle & - & $\mathrm{x}$ \\
\hline \multirow[t]{7}{*}{ Surface decontamination } & & XPS & - & $\mathrm{x}$ \\
\hline & Hydroxilation & XPS & & $\mathrm{x}$ \\
\hline & Formation & FTIR & $\mathrm{x}$ & - \\
\hline & Nature & DRFTIR & $\mathrm{x}$ & - \\
\hline & Thickness & AFM & $\mathrm{x}$ & - \\
\hline & No growing area & AFM & $\mathrm{x}$ & - \\
\hline & Wettability & Water contact angle & - & $\mathrm{x}$ \\
\hline
\end{tabular}

SEM: Scanning electron microscopy, EDX: Energy dispersive X-ray analysis, XPS: X-ray photoelectron spectroscopy, DRIFT: Diffuse reflectance infrared Fourier transform spectroscopy, AFM: Atomic force microscopy. 
adsorbates pure [91]. The preparation conditions support the necessity of sterility of the implant.

Stable SAMs are obtained with the correct above reported procedures (cleaning, hydroxilating and deposition for phosphonic acid).

If chemical pretreatments are not carefully controlled it is possible to have surface morphology modification, resulting the substrate corrosion and formation of a very porous surface, which is undesirable [70].

Direct SAMs formation on $\mathrm{Ti}$ is limited by the low surface hydroxyl $(\mathrm{OH})$ group content of the Ti native oxide surface; only about $15 \%$ of surface $\mathrm{O}$ is due to $\mathrm{OH}$.

Enhanced surface hydroxylation may be obtained by physical or chemical treatments.

The reproducibility of the SAM treatment could be assessed in the same way of the characterization above reported.

The stability of SAMs under physiological or sterilization conditions is crucial for successfully using this technique to coat medical implants [92].

While sulfur-surface (gold, indium coated tin oxide and so on) self-assembling is used for fabrication of individual monomolecular modification on the surface, for Ti surfaces it is necessary to use phosphonic acids or silanes as attaching groups.

It is known that the modification of Ti surface with calcium phosphate (CP) and/or hydroxyapatite (HA) coatings have attracted most research interest because of the substantial improvements achieved in terms of osteointegration.

SAMs can improve the CP or HA coating on titanium substrates inducing their mineralization with high crystallinity and relatively strong interfacial bonds with the substrates [93-99].

A crucial aspect to promote a good crystallization of HA is the strength and the organization of the SAMs film; these are strongly affected by the influence of Ti surface properties, such as chemical composition (hydroxylation of the surface) and morphology (formation of cervices), obtained by chemical pre-treatments.

The critical role played by crystalline or semicrystalline nature of the SAM in order to improve cell and osteoactivity must be investigated.

\section{Conclusions}

The success in implant dentistry is related with its micro and nano roughness surface characteristics.

Therefore the SAMs films may be an important innovative and alternative technique to the traditional surface treatments able to improve the healing process.

Although SAM formation provides a simple strategy to form ultrathin and thermodynamically stable organic films (also for non-planar feature surfaces) some limita- tions could restrict their applications. The problems related with SAMs stability and the reproducibility of the monolayer treatment must be solved especially in order to the bone host tissue and the applicability in the oral and maxillofacial implant surgical technique.

As future trends more designed and built up technique of SAMs could condition the different physiological and pathological process. Therefore more experimental studies of SAMs growth on cpTi and its alloys as well as in vitro and in vivo animal studies are request.

\section{Acknowledgements}

GF is grateful to the Italian National Project PRIN2009 (Prot. 2009N9N8RX "Chemistry in Motion"), for the financial support.

\section{REFERENCES}

[1] J. A. Shibli, S. Grassi, L. C. de Figueiredo, M. Feres, E. Marcantonio Jr., G. Iezzi and A. Piattelli, "Influence of Implant Surface Topography on early Osseointegration: A Histological Study in Human Jaws," Journal of Biomedical Materials Research Part B: Applied Biomaterials, Vol. 80B, No. 2, 2007, pp. 377-385.

[2] S. Tetè, F. Mastrangelo, R. Quaresima, R. Vinci, G. Sammartino, L. Stuppia and E. Gherlone, "Influence of Novel Nano-Titanium Implant Surface on Human Osteoblast Behavior and Growth," Implant Dentistry, Vol. 19, No. 6, 2010, pp. 520-530. doi:10.1097/ID.0b013e3182002eac

[3] A. Wennemberg and T. Albrektsson, "On Implant Surfaces: A Review of Current Knowledge and Opinions," The International Journal of Oral and Maxillofacial Implants, Vol. 25, No. 1, 2010, pp. 63-74.

[4] K. Thomas and S. D. Cook, "Relationship between Surface Characteristics and the Degree of Bone-Implant Integration," Journal of Biomedical Materials Research, Vol. 26, No. 6, 1992, pp. 831-832. doi: $10.1002 / \mathrm{jbm} .820260612$

[5] T. Albrektsson, P. I. Branemark, H. A. Hansson and J. Lindstrom, "Osseointegrated Titanium Implants," Acta Orthopaedica Scandinavica, Vol. 52, 1981, pp. 155-170. doi:10.3109/17453678108991776

[6] N. S. Peckitt, "Stereoscopic Lithography: Customized Titanium Implants in Orofacial Reconstruction," British Journal of Oral and Maxillofacial Surgery, Vol. 37, No. 5, 1999, pp. 353-369. doi:10.1054/bjom.1999.0070

[7] A. Gaggl, G. Schultes, W. D. Muller and H. Karcher, "Scanning Electron Microscopical Analysis of LaserTreated Titanium Implant Surfacesa Comparative Study," Biomaterials, Vol. 21, No. 10, 2000, pp. 1067-1073. doi:10.1016/S0142-9612(00)00002-8

[8] P.-F. Chauvy, P. Hoffmann and D. Landolt, "Applications of Laser Lithography on Oxide Film to Titanium Micromachining," Applied Surface Science, Vol. 208-209, 2003, pp. 165-170. doi:10.1016/S0169-4332(02)01361-2 
[9] P.-F. Chauvy, P. Hoffmann and D. Landolt, "Electrochemical Micromachining of Titanium Using Laser Oxide Film Lithography: Excimer Laser Irradiation of Anodic Oxide," Applied Surface Science, Vol. 211, No. 1-4, 2003, pp. 113-127. doi:10.1016/S0169-4332(03)00256-3

[10] A. Kurella and N. B. Dahotre, "Review Paper: Surface Modification for Bioimplants: The Role of Laser Surface Engineering," Journal of Biomaterials Applications, Vol. 20, No. 1, 2005, pp. 5-50. doi:10.1177/0885328205052974

[11] R. Lahoza, J. P. Espinos, G. F. De la Fuente and A. R. Gonzalez-Elipe, "In Situ XPS Studies of Laser Induced Surface Cleaning and Nitridation of Ti," Surface Coating Technologies, Vol. 202, No. 8, 2008, pp. 1486-1492. doi:10.1016/j.surfcoat.2007.06.061

[12] A. Heinrich, K. Dengler, T. Koerner, C. Haczek, H. Deppe and B. Stritzker, "Laser-Modified Titanium Implants for Improved Cell Adhesion," Lasers Medicine Science, Vol. 23, No. 1, 2008, pp. 55-58. doi:10.1007/s10103-007-0460-Z

[13] K. Yoon, K. Yang and H. Lee, "Fabrication of Polycrystalline $\mathrm{TiO}_{2}$ Nanopatterns by $\mathrm{TiO}_{2}$ Sol Base Imprint Lithography," Thin Solid Films, Vol. 518, No. 1, 2009, pp. 126-129. doi:10.1016/j.tsf.2009.07.056

[14] I. N. Zavestovskaya, "Laser Nanostructuring of Materials Surfaces," Quantum Electron, Vol. 40, No. 11, 2010, pp. 942-954. doi:10.1070/QE2010v040n11ABEH014447

[15] P. Rajesh, C. V. Muraleedharan, M. Komath and H. Varma, "Laser Surface Modification of Titanium Substrate for Pulsed Laser Deposition of Highly Adherent Hydroxyapatite," Journal of Materials Science: Materials Medicine, Vol. 22, No. 7, 2011, pp. 1671-1679. doi:10.1007/s10856-011-4342-3

[16] R. A. Delgado-Ruíz, J. L. Calvo-Guirado, P. Moreno, J. Guardia, G. Gomez-Moreno, J. E. Mate-Sánchez, P. Ramirez-Fernández and F. Chiva, "Femtosecond Laser Microstructuring of Zirconia Dental Implants," Journal of Biomedical Materials Research Part B: Applied Biomaterials, Vol. 96B, No. 1, 2011, pp. 91-100.

doi:10.1002/jbm.b.31743

[17] A. Pelaez-Vargas, D. Gallego-Perez, M. MagallanesPerdomo, M. H. Fernandes, D. J. Hansford, A. H. De Aza, P. Pena and F. J. Monteiro, "Isotropic Micropatterned Silica Coatings on Zirconia Induce Guided Cell Growth for Dental Implants," Dental Materials, Vol. 27, No. 6, 2011, pp. 581-589. doi:10.1016/j.dental.2011.02.014

[18] N. A. Riedel, J. D. Williams and K. C. Popat, "Ion Beam Etching Titanium for Enhanced Osteoblast Response," Journal of Materials Science, Vol. 46, No. 18, 2011, pp. 6087-6095. doi:10.1007/s10853-011-5571-z

[19] H.-H. Park, X. Zhang, S.-W. Lee, D.-J. Jeong, S.-M.o Lee, K.-D. Kim, D.-G. Choi, J.-H. Choi, J. Lee, E.-S. Lee, H. K. Kang, H.-H. Park, R. H. Hill and J.-H. Jeong, "Optical Characterization of Anatase $\mathrm{TiO}_{2}$ Films Patterned by Direct Ultraviolet-Assisted Nanoimprint Lithography," Microelectronic Engineering, Vol. 88, No. 6, 2011, pp. 923-928. doi:10.1016/j.mee.2010.12.018

[20] A. A. Campbell, G. E. Fryxell, J. C. Linehan and G. L.
Graff, "Surface-Induced Mineralization: A New Method for Producing Calcium Phosphate Coatings," Journal of Biomedical Materials Research, Vol. 32, No. 1, 1996, pp. 111-118.

doi:10.1002/(SICI)1097-4636(199609)32:1<111::AID-JB M13>3.0.CO;2-P

[21] C. B. Mao, H. D. Li, F. Z. Cui, Q. G. Feng, H. Wang and C. L. Ma, "Oriented Growth of Hydroxyapatite on (0001) Textured Titanium with Functionalized Self-Assembled Silane Monolayer as Template," Journal of Materials Chemistry, Vol. 8, No. 12, 1998, pp. 2795-2801. doi:10.1039/a801384e

[22] Q. Liu, J. Ding, F. K. Mante, S. L. Wunder and G. R. Baran, "The Role of Surface Functional Groups in Calcium Phosphate Nucleation on Titanium Foil: A SelfAssembled Monolayer Technique," Biomaterials, Vol. 23, No. 15, 2002, pp. 3103-3111. doi:10.1016/S0142-9612(02)00050-9

[23] S. P. Huang, K. C. Zhou, Y. Liu and B. Y. Huang, "Controlled Crystallization of Hydroxyapatite under Hexadecylamine Self-Assembled Monolayer," Transactions of Nonferrous Metals Society of China, Vol. 13, 2003, pp. 595-599.

[24] P. J. Majewski and G. Allidi, "Synthesis of Hydroxyapatite on Titanium Coated with Organic Self-Assembled Monolayers," Materials Science and Engineering a-Structural Materials Properties Microstructure and Processing, Vol. 420, 2006, pp. 13-20.

[25] R. Beutner, J. Michael, B. Schwenzer and D. Scharnweber, "Biological Nano-Functionalization of TitaniumBased Biomaterial Surfaces: A Flexible Toolbox," Journal of the Royal Society Interface, Vol. 7, Suppl. 1, 2010, pp. S93-S105. doi:10.1098/rsif.2009.0418.focus

[26] G. Mendonca, D. B. S. Mendonca, F. J. L. Aragao and L. F. Cooper, "Advancing Dental Implant Surface Technology_From Micron-To Nanotopography," Biomaterials, Vol. 29, 28, 2008, pp. 3822-3835.

[27] J. Tan and W. M. Saltzman, "Biomaterials with Hierarchically Defined Micro- and Nanoscale Structure," Biomaterials, Vol. 25, No. 17, 2004, pp. 3593-3601. doi:10.1016/j.biomaterials.2003.10.034

[28] R. G. Nuzzo and D. L. Allara, "Adsorption of Bifunctional Organic Disulfides on Gold Surfaces," Journal of the American Chemical Society, Vol. 105, No. 13, 1983, pp. 4481-4483. doi:10.1021/ja00351a063

[29] D. L. Allara and R. G. Nuzzo, "Spontaneously Organized Molecular Assemblies. 1. Formation, Dynamics and Physical-Properties of Normal-Alkanoic Acids Adsorbed from Solution on an Oxidized Aluminum Surface," Langmuir, Vol. 1, No. 1, 1985, pp. 45-52. doi:10.1021/la00061a007

[30] D. L. Allara and R. G. Nuzzo, "Spontaneously Organized Molecular Assemblies. 2. Quantitative Infrared Spectroscopic Determination of Equilibrium Structures of Solution-Adsorbed Normal-Alkanoic Acids on an Oxidized Aluminum Surface," Langmuir, Vol. 1, No. 1, 1985, pp. 52-66. doi:10.1021/la00061a008

[31] R. G. Nuzzo, F. A. Fusco and D. L. Allara, "Spontane- 
ously Organized Molecular Assemblies. 3. Preparation and Properties of Solution Adsorbed Monolayers of Organic Disulfides on Gold Surfaces," Journal of the American Chemical Society, Vol. 109, No. 8, 1987, pp. 2358-2368. doi:10.1021/ja00242a020

[32] E. B. Troughton, C. D. Bain, G. M. Whitesides, R. G. Nuzzo, D. L. Allara and M. D. Porter, "Monolayer Films Prepared by the Spontaneous Self-Assembly of Symmetrical and Unsymmetrical Dialkyl Sulfides from Solution onto Gold Substrates-Structure, Properties and Reactivity of Constituent Functional-Groups," Langmuir, Vol. 4, No. 2, 1988, pp. 365-385. doi:10.1021/la00080a021

[33] J. C. Love, L. A. Estroff, J. K. Kriebel, R. G. Nuzzo and G. M. Whitesides, "Self-Assembled Monolayers of Thiolates on Metals as a Form of Nanotechnology," Chemical Reviews, Vol. 105, No. 4, 2005, pp. 1103-1169. doi:10.1021/cr0300789

[34] J. G. Vos, R. J. Forster and T. E. Keyes, "Interfacial Supramolecular Assemblies," Wiley, John \& Sons, Inc., New York, 2003, pp. 88-94. doi:10.1002/0470861517

[35] A. Ulman, "Formation and Structure of Self-Assembled Monolayers," Chemical Reviews, Vol. 96, No. 4, 1996, pp. 1533-1554. doi:10.1021/cr9502357

[36] G. M. Whitesides, J. K. Kriebel and J. C. Love, "Molecular Engineering of Surfaces Using Self-Assembled Monolayers," Science Progress, Vol. 88, No. 1, 2005, pp. 17-48. doi:10.3184/003685005783238462

[37] A. Raman, R. Quinones, L. Barriger, R. Eastman, A. Parsi and E. S. Gawalt, "Understanding Organic Film Behavior on Alloy and Metal Oxides," Langmuir, Vol. 26, No. 3, 2010, pp. 1747-1754. doi:10.1021/la904120s

[38] L. F. Rozsnyai and M. S. Wrighton, "Controlling the Adhesion of Conducting Polymer Films with Patterned Self-Assembled Monolayers," Chemistry of Materials, Vol. 8, No. 2, 1996, pp. 309-311. doi: $10.1021 / \mathrm{cm} 9502838$

[39] K. Nozawa, H. Nishihara and K. Aramaki, "Chemical Modification of Alkanethiol Monolayers for Protecting Iron against Corrosion," Corrosion Science, Vol. 39, No. 9, 1997, pp. 1625-1639. doi:10.1016/S0010-938X(97)00065-6

[40] S. Svedhem, C. A. Hollander, J. Shi, P. Konradsson, B. Liedberg and S. C. T. Svensson," Synthesis of a Series of Oligo(ethylene glycol)-Terminated Alkanethiol Amides Designed to Address Structure and Stability of Biosensing Interfaces," Journal of Organic Chemistry, Vol. 66, No. 13, 2001, pp. 4494-4503. doi:10.1021/jo0012290

[41] B. C. Kovaric, B. Kokona, A. D. Schwab, M. A. Twomey, J. C. De Paula and R. Fairman, "Self-Assembly of Peptide Porphyrin Complexes: Toward the Development of Smart Biomaterials," Journal of the American Chemical Society, Vol. 128, No. 13, 2006, pp. 4166-4167. doi:10.1021/ja056357q

[42] D. A. Wang, L. X. Feng, J. Ji, Y. H. Sun, X. X. Zheng and J. H. Elisseeff, "Novel Human Endothelial Cell-Engineered Polyurethane Biomaterials for Cardiovascular Biomedical Applications," Journal of Biomedical Mate- rials Research Part A, Vol. 65A, No. 4, 2003, pp. 498 510. doi:10.1002/jbm.a.10533

[43] Y. G. Jiang, Z. Q. Wang, X. Yu, F. Shi, H. P. Xu and X. Zhang, "Self-Assembled Monolayers of Dendron Thiols for Electrodeposition of Gold Nanostructures: Toward Fabrication of Superhydrophobic/Superhydrophilic Surfaces and pH-Responsive Surfaces," Langmuir, Vol. 21, No. 5, 2005, pp. 1986-1990. doi:10.1021/la047491b

[44] B. S. Park, S. J. Heo, C. S. Kim, J.-E. Oh, J.-M. Kim, G. Lee, W. H. Park, C.-P. Chung and B.-M. Min, "Effects of Adhesion Molecules on the Behavior of Osteoblast-Like Cells and Normal Human Fibroblasts on Different Titanium Surfaces," Journal of Biomedical Materials Research Part A, Vol. 74, No. 4, 2005, pp. 640-651. doi:10.1002/jbm.a.30326

[45] J. D. Cox, M. S. Curry, S. K. Skirboll, P. L. Gourley and D. Y. Sasaki, "Surface Passivation of a Microfluidic Device to Glial Cell Adhesion: A Comparison of Hydrophobic and Hydrophilic SAM Coatings," Biomaterials, Vol. 23, No. 3, 2002, pp. 929-935. doi:10.1016/S0142-9612(01)00205-8

[46] F. R. F. Fan, Y. X. Yao, L. T. Cai, L. Cheng, J. M. Tour and A. J. Bard, "Structure-Dependent Charge Transport and Storage in Self-Assembled Monolayers of Compounds of Interest in Molecular Electronics: Effects of Tip Material, Headgroup, and Surface Concentration," Journal of the American Chemical Society, Vol. 126, No. 12, 2004, pp. 4035-4042. doi:10.1021/ja0359815

[47] S. Nitahara, T. Akiyama, S. Inoue and S. Yamada, "A Photoelectronic Switching Device Using a Mixed SelfAssembled Monolayer," The Journal of Physical Chemistry B, Vol. 109, No. 9, 2005, pp. 3944-3948. doi:10.1021/jp046776u

[48] Y. S. Lee, "Self-Assembly and Nanotechnology: A Force Balance Approach," John Wiley \& Sons, New York, 2008. doi:10.1002/9780470292525

[49] N. Spencer, "Tailoring Surfaces: Modifying Surface Composition and Structure for Applications in Tribology, Biology and Catalysis," World Scientific Publishing Co. Pte. Ltd., Singapore, 2010.

[50] S. K. Arya, M. Datta and B. D. Malhotra, "Application of Self-Assembled Monolayers to Cholesterol Biosensor: Preparation, Characterization and Application of Some Monolayers to Cholesterol Biosensor," LAP Lambert Academic Publishing, AG \& Co KG, Saarbrücken, 2011.

[51] F. Schreiber, "Structure and Growth of Self-Assembling Monolayers," Progress in Surface Science, Vol. 65, No. 5-8, 2000, pp. 151-256. doi:10.1016/S0079-6816(00)00024-1

[52] D. K. Schwartz, "Mechanisms and Kinetics of Self-Assembled Monolayer Formation," Annual Review of Physical Chemistry, Vol. 52, 2001, pp. 107-137. doi:10.1146/annurev.physchem.52.1.107

[53] O. Azzaroni, M. E. Vela, H. Martin, A. H. Creus, G. Andreasen and R. C. Salvarezza, "Electrodesorption Kinetics and Molecular Interactions at Negatively Charged SelfAssembled Thiol Monolayers in Electrolyte Solutions," 
Langmuir, Vol. 17, No. 21, 2001, pp. 6647-6654. doi:10.1021/la010019v

[54] T. Sawaguchi, Y. Sato and F. Mizutani, "Ordered Structures of Self-Assembled Monolayers of 3-Mercaptopropionic Acid on Au(111): In Situ Scanning Tunneling Microscopy Study," Physical Chemistry Chemical Physics, Vol. 3, No. 16, 2001, pp. 3399-3404. doi:10.1039/b101897n

[55] A. E. Kaifer, "Supramolecular Electrochemistry," Wiley VCH, Coral Gables, 2001, pp. 191-206.

[56] C. Vericat, M. E. Vela and R. C. Salvarezza, "Self-Assembled Monolayers of Alkanethiols on Au(111): Surface Structures, Defects and Dynamics," Physical Chemistry Chemical Physics, Vol. 7, No. 18, 2005, pp. 3258-3268. doi:10.1039/b505903h

[57] E. Delamarche, B. Michel, H. Kang and C. Gerber, "Thermal-Stability of Self-Assembled Monolayers," Langmuir, Vol. 10, No. 11, 1994, pp. 4103-4108. doi:10.1021/la00023a033

[58] S. Ebbens, D. Hutt and C. Q. Liu, "The Thermal Stability of Alkanethiol Self-Assembled Monolayers on Copper for Fluxless Soldering Applications," IEEE Transactions on Components and Packaging Technologies, Vol. 33, No. 2, 2010, pp. 251-259. doi:10.1109/TCAPT.2010.2041779

[59] G. W. Stone, S. G. Ellis, D. A. Cox, J. Hermiller, C. O’Shaughnessy, J. T. Mann, M. Turco, R. Caputo, P. Bergin, J. Greenberg, J. J. Popma, M. E. Russell and T.-I. Investigators, "A Polymer-Based, Paclitaxel-Eluting Stent in Patients with Coronary Artery Disease," New England Journal of Medicine, Vol. 350, 2004, pp. 221-231. doi:10.1056/NEJMoa032441

[60] M. Morice, P. W. Serruys, J. E. Sousa, J. Fajadet, E. B. Hayashi, M. Perin, A. Colombo, G. Schuler, P. Barragan, G. Guagliumi, F. Molnar, R. Falotico and R. S. Grp, "A Randomized Comparison of a Sirolimus-Eluting Stent with a Standard Stent for Coronary Revascularization," New England Journal of Medicine, Vol. 346, No. 23, 2002, pp. 1773-1780. doi:10.1056/NEJMoa012843

[61] M. Diefenbeck, T. Muckley and G. O. Hofmann, "Prophylaxis and Treatment of Implant-Related Infections by Local Application of Antibiotics," Injury-International Journal of the Care of the Injured, Vol. 37, No. 2, 2006, pp. 95-104.

[62] G. Schmidmaier, M. Lucke, B. Wildemann, N. P. Haas and M. Raschke, "Prophylaxis and Treatment of ImplantRelated Infections by Antibiotic-Coated Implants: A Review," Injury-International Journal of the Care of the Injured, Vol. 37, No. 2, 2006, pp. 105-112.

[63] G. Mani, D. M. Johnson, D. Marton, M. D. Feldman, D. Patel, A. A. Ayon and C. M. Agrawal, "Drug Delivery from Gold and Titanium Surfaces Using Self-Assembled Monolayers," Biomaterials, Vol. 29, No. 34, 2008, pp. 4561-4573. doi:10.1016/j.biomaterials.2008.08.014

[64] B. Kasemo and J. Lausmaa, "Aspect of Surface Physics on Titanum Implants," Swedish Dental Journal, Vol. 28, 1983, pp. 19-36.
[65] J. Lausmaa, and B. Kasemo, "Surface Spectroscopic Characterization of Titanium Implant Materials," Applied Surface Science, Vol. 44, No. 2, 1990, pp. 133-146. doi:10.1016/0169-4332(90)90100-E

[66] G. Radegran, J. Lausmaa, L. Matsson, U. Rolander and B. Kasemo, "Preparation of Ultra-Thin Oxide Window on Titanium for Tem Analysis," Journal of Electron Microscopy Techniques, Vol. 19, No. 1, 1991, pp. 99-106. doi:10.1002/jemt.1060190110

[67] I. Olefjord and S. Hansson, "Surface Analysis of Four Dental Implant Systems," The International Journal of Oral and Maxillofacial Implants, Vol. 8, No. 1, 1993, pp. $32-40$.

[68] J. L. Ong, L. C. Lucas, G. N. Raikar, R. Connatser and J. C. Gregory, "Spectroscopic Characterization of Passivated Titanium in a Physiologic Solution," Journal of Materials Science-Materials in Medicine, Vol. 6, No. 2, 1995, pp. 113-119. doi:10.1007/BF00120418

[69] B. Feng, J. Y. Chen, S. K. Qi, L. He, J. Z. Zhao and X. D. Zhang, "Characterization of surface Oxide Films on Titanium and Bioactivity," Journal of Materials Science: Materials in Medicine, Vol. 13, No. 5, 2002, pp. 457-464. doi:10.1023/A:1014737831371

[70] E. Ajami and K. F. Aguey-Zinsou, "Formation of OTS Self-Assembled Monolayers at Chemically Treated Titanium Surfaces," Journal of Materials Science-Materials in Medicine, Vol. 22, No. 8, 2011, pp. 1813-1824. doi:10.1007/s10856-011-4356-X

[71] R. Hofer, M. Textor and N. D. Spencer, "Alkyl Phosphate Monolayers Self-Assembled from Aqueous Solution onto Metal Oxide Surfaces," Langmuir, Vol. 17, No. 13, 2001, pp. 4014-4020. doi:10.1021/1a001756e

[72] R. De Palma, W. Laureyn, F. Frederix, K. Bonroy, J. J. Pireaux, G. Borghs and G. Maes, "Formation of Dense Self-Assembled Monolayers of ( $n$-Decyl)trichlorosilanes on $\mathrm{Ta} / \mathrm{Ta}_{2} \mathrm{O}_{5}$," Langmuir, Vol. 23, No. 2, 2007, pp. 443451. doi:10.1021/1a061951e

[73] W. Gao, L. Dickinson, C. Grozinger, F. G. Morin and L. Reven, "Self-Assembled Monolayers of Alkylphosphonic Acids on Metal Oxides," Langmuir, Vol. 12, No. 26, 1996, pp. 6429-6435. doi:10.1021/la9607621

[74] S. Pawsey, K. Yach and L. Reven, "Self-Assembly of Carboxyalkylphosphonic Acids on Metal Oxide Powders," Langmuir, Vol. 18, No. 13, 2002, pp. 5205-5212. doi:10.1021/1a015749h

[75] R. Quinones and E. S. Gawalt, "Study of the Formation of Self-Assembled Monolayers on Nitinol," Langmuir, Vol. 23, No. 20, 2007, pp. 10123-10130. doi:10.1021/la701110p

[76] M. Yoshinari, T. Hayakawa, K. Matsuzaka, T. Inoue, Y. Oda, M. Shimono, T. Ide and T. Tanaka, "Oxygen Plasma Surface Modification Enhances Immobilization of Simvastatin Acid," Biomedical Research-Tokyo, Vol. 27, 2006, pp. 29-36. doi:10.2220/biomedres.27.29

[77] E. S. Gawalt, M. J. Avaltroni, N. Koch and J. Schwartz, "Self-Assembly and Bonding of Alkanephosphonic Acids 
on the Native Oxide Surface of Titanium," Langmuir, Vol. 17, No. 19, 2001, pp. 5736-5738. doi:10.1021/la010649x

[78] S. Tosatti, R. Michel, M. Textor and N. D. Spencer, "Self-Assembled Monolayers of Dodecyl and HydroxyDodecyl Phosphates on Both Smooth and Rough Titanium and Titanium Oxide Surfaces," Langmuir, Vol. 18, 2002, pp. 3537-3548. doi:10.1021/la011459p

[79] M. Zwahlen, S. Tosatti, M. Textor and G. Hahner, "Orientation in Methyl- and Hydroxyl-Terminated Self-Assembled Alkanephosphate Monolayers on Titanium Oxide Surfaces Investigated with Soft X-Ray Absorption," Langmuir, Vol. 18, No. 10, 2002, pp. 3957-3962. doi:10.1021/la015692z

[80] P. H. Mutin, G. Guerrero and A. Vioux, "Hybrid Materials from Organophosphorus Coupling Molecules," Journal of Materials Chemistry, Vol. 15, No. 35-36, 2005, pp. 3761-3768. doi:10.1039/b505422b

[81] T. Knieling, W. Lang and W. Benecke, "Gas Phase Hydrophobisation of MEMS Silicon Structures with SelfAssembling Monolayers for Avoiding In-Use Sticking," Sensors and Actuators B: Chemical, Vol. 126, No. 1, 2007, pp. 13-17. doi:10.1016/j.snb.2006.10.023

[82] Y. L. Wang and M. Lieberman, "Growth of Ultrasmooth Octadecyltrichlorosilane Self-Assembled Monolayers on $\mathrm{SiO}_{2}$," Langmuir, Vol. 19, No. 4, 2003, pp. 1159-1167. doi:10.1021/la020697x

[83] A. Kanta, R. Sedev and J. Ralston, "The Formation and Stability of Self-Assembled Monolayers of Octadecylphosphonic Acid on Titania," Colloids and Surfaces A: Physicochemical and Engineering Aspects, Vol. 291, No. 1-3, 2006, pp. 51-58. doi:10.1016/j.colsurfa.2005.12.057

[84] B. M. Silverman, K. A. Wieghaus and J. Schwartz, "Comparative Properties of Siloxane vs Phosphonate Monolayers on a Key Titanium Alloy," Langmuir, Vol. 21, No. 1, 2005, pp. 225-228. doi:10.1021/la0482271

[85] G. Zorn, I. Gotman, E. Y. Gutmanas, R. Adadi, G. Salitra and C. N. Sukenik, "Surface Modification of Ti45Nb Alloy with an Alkylphosphonic Acid Self-Assembled Monolayer," Chemistry of Materials, Vol. 17, No. 16, 2005, pp. 4218-4226. doi:10.1021/cm050477f

[86] G. Zorn, I. Gotman, E. Y. Gutmanas, R. Adadi and C. N. Sukenik, "Surface Modification of Ti45Nb Alloy by Immobilization of RGD Peptide via Self Assembled Monolayer," Journal of Materials Science-Materials in Medicine, Vol. 18, No. 7, 2007, pp. 1309-1315. doi:10.1007/s10856-006-0117-7

[87] N. Adden, L. J. Gamble, D. G. Castner, A. Hoffmann, G. Gross and H. Menzel, "Phosphonic Acid Monolayers for Binding of Bioactive Molecules to Titanium Surfaces," Langmuir, Vol. 22, No. 19, 2006, pp. 8197-8204. doi:10.1021/la060754c

[88] N. Adden, L. J. Gamble, D. G. Castner, A. Hoffmann, G. Gross and H. Menzel, "Synthesis and Characterization of Biocompatible Polymer Interlayers on Titanium Implant Materials," Biomacromolecules, Vol. 7, No. 9, 2006, pp. 2552-2559. doi:10.1021/bm060473j

[89] S. Clair, F. Variola, M. Kondratenko, P. Jedrzejowski, A.
Nanci, F. Rosei and D. F. Perepichka, "Self-Assembled Monolayer of Alkanephosphoric Acid on Nanotextured Ti," Journal of Chemical Physics, Vol. 128, No. 14, 2008, Article ID 144705, pp. 1-6.

[90] E. L. Hanson, J. Schwartz, B. Nickel, N. Koch and M. F. Danisman, "Bonding Self-Assembled Compact Organophosphonate Monolayers to the Native Oxide Surface of Silicon," Journal of the American Chemical Society, Vol. 125, No. 51, 2003, pp. 16074-16080. doi: $10.1021 / \mathrm{ja} 035956 \mathrm{z}$

[91] A. Nanci, J. D. Wuest, L. Peru, P. Brunet, V. Sharma, S. Zalzal, M. D. McKee, "Chemical Modification of Titanium Surfaces for Covalent Attachment of Biological Molecules," Journal of Biomedical Materials Research, Vol. 40, No. 2, 1998, pp. 324-335.

doi:10.1002/(SICI)1097-4636(199805)40:2<324::AID-JB $\mathrm{M} 18>3.0 . \mathrm{CO} ; 2-\mathrm{L}$

[92] G. Mani, D. M. Johnson, D. Marton, V. L. Dougherty, M. D. Feldman, D. Patel, A. A. Ayon, and C. M. Agrawal "Stability of Self-Assembled Monolayers on Titanium and Gold," Langmuir, Vol. 24, No. 13, 2008, pp. 6774 6784. doi:10.1021/la8003646

[93] A. A. Campbell, G. E. Fryxell, J. C. Linehan and G. L. Graff, "Surface-Induced Mineralization: A New Method for Producing Calcium Phosphate Coatings," Journal of Biomedical Materials Research, Vol. 32, No. 1, 1996, pp. 111-118.

doi:10.1002/(SICI)1097-4636(199609)32:1<111::AID-JB $\mathrm{M} 13>3.0 . \mathrm{CO} ; 2-\mathrm{P}$

[94] S. P. Huang, K. C. Zhou, Y. Liu and B. Y. Huang, "Controlled Crystallization of Hydroxyapatite under Hexadecylamine Self-Assembled Monolayer," Transactions of Nonferrous Metals Society of China, Vol. 13, No. 3, 2003, pp. 595-599.

[95] Q. Liu, J. Ding, F. K. Mante, S. L. Wunder and G. R. Baran, "The Role of Surface Functional Groups in Calcium Phosphate Nucleation on Titanium Foil: A SelfAssembled Monolayer Technique," Biomaterials, Vol. 23, No. 15, 2002, pp. 3103-3111. doi:10.1016/S0142-9612(02)00050-9

[96] P. J. Majewski and G. Allidi, "Synthesis of Hydroxyapatite on Titanium Coated with Organic Self-Assembled Monolayers," Materials Science and Engineering A: Structural Materials Properties Microstructure and Processing, Vol. 420, No. 1-2, 2006, pp. 13-20. doi:10.1016/j.msea.2006.01.022

[97] C. B. Mao, H. D. Li, F. Z. Cui, Q. G. Feng, H. Wang and C. L. Ma, "Oriented Growth of Hydroxyapatite on (0001) Textured Titanium with Functionalized Self-Assembled Silane Monolayer as Template," Journal of Materials Chemistry, Vol. 8, No. 12, 1998, pp. 2795-2801. doi:10.1039/a801384e

[98] Y. Masuda, T. Sugiyama and K. Koumoto, "Micropatterning of Anatase $\mathrm{TiO}_{2}$ Thin Films from an Aqueous Solution by a Site-Selective Immersion Method," Journal of Materials Chemistry, Vol. 12, No. 9, 2002, pp. 26432647. doi:10.1039/b203786f

[99] P. X. Zhu, Y. Masuda and K. Koumoto, “A Novel Ap- 
proach to Fabricate Hydroxyapatite Coating on Titanium Substrate in an Aqueous Solution," Journal of the Ce- ramic Society of Japan, Vol. 109, No. 8, 2001, pp. 676680. doi:10.2109/jcersj.109.1272_676 